\title{
Are IVS4 SNPs of OLR1 gene associated with coronary artery disease: Is there a linkage between IVS4 SNPs?
}

\author{
Özlem Kurnaz-Gömleksiz ${ }^{1, B-D}$, Özlem Kücükhüseyin ${ }^{1, B, D}$, Elif Özkök2,C, \\ Zehra Buğra' ${ }^{3, B, C}$, Oğuz Öztürk ${ }^{1, E, F}$, Hülya Yilmaz-Aydoğan ${ }^{1, A, C-F}$ \\ 1 Department of Molecular Medicine, Institute for Experimental Medicine, Istanbul University, Turkey \\ ${ }^{2}$ Department of Neuroscience, Institute for Experimental Medicine, Istanbul University, Turkey \\ ${ }^{3}$ Department of Cardiology, Faculty of Medicine, Istanbul University, Turkey \\ A - research concept and design; $B$ - collection and/or assembly of data; $C$ - data analysis and interpretation; \\ $D$ - writing the article; $E$ - critical revision of the article; $F$ - final approval of the article
}

\section{Address for correspondence \\ Hulya Yilmaz-Aydogan}

E-mail: hulyayilmaz6@gmail.com

\section{Funding sources}

The present work was supported by the Research Fund of Istanbul University, Turkey. Project No. T-966/06102006.

Conflict of interest

None declared

Received on May 17, 2016

Reviewed on June 27, 2016

Accepted on January 10, 2017

DOI

$10.17219 /$ acem $/ 68395$

\section{Copyright}

Copyright by Author(s)

This is an article distributed under the terms of the

Creative Commons Attribution Non-Commercial License

(http://creativecommons.org/licenses/by-nc-nd/4.0/)

\section{Abstract}

Background. The OLR1 gene has been identified as a candidate gene for coronary artery disease (CAD). Six single-nucleotide polymorphisms (SNPS) of the OLR1 gene located within intron 4 (IVS4-27G>C, IVS4-73C $>$ T, IVS4-14A $>$ G), intron 5 (IVS5-70A >G, IVS5-27G $>$ T) and 3'UTR (188C >T) comprise a linkage disequilibrium (LD) block, which is strongly associated with the elevated risk of CAD.

0bjectives. We aimed to investigate the effects of the $0 L R 1$ IVS4-14A $>G$ and $-73 C>T$ SNPs on metabolic parameters in Turkish CAD patients, and the linkage between these 2 genetic variants.

Material and methods. The present study was carried out in 97 CAD patients and 78 healthy individuals. The OLR1 IVS4 genotypings were performed by polymerase chain reaction - restriction fragment length polymorphism (PCR-RFLP) method.

Results. Serum high-density lipoprotein (HDL) cholesterol levels and body mass index (BMI) were higher in control subjects with IVS4-73CC genotype than in T allele carriers (CT+TT) (respectively, $p=0.002$ and $p=0.024)$, while BMI values were lower in patients with $C($ genotype $(p=0.046)$. Patients with IVS4-14G allele $(A G+G G)$ had a statistically higher low-density lipoprotein (LDL) cholesterol level $(p=0.027)$ than patients with -14AA genotype. Also the systolic blood pressure (SBP) levels were statistically higher in IVS4$73 C$ allele carriers (CT+CC) than in non-carriers (TT) $(p=0.045)$. A strong linkage between IVS4-14A>G and $-73 C>T$ SNPs of the $O L R T$ gene was detected in patients $\left(D^{\prime}=0.76\right)$.

Conclusions. Our results indicated that the intron $4-14 A>G$ and $-73 C>T$ SNPs of the OLRT gene can be inherited together. The present data also suggests that the OLR1 gene may contribute to the development of hypercholesterolemia in patients with CAD.

Key words: single nucleotide polymorphism, coronary artery disease, serum lipids, linkage disequilibrium, OLRT gene 


\section{Introduction}

Elevated plasma and tissue levels of oxidized low-density lipoprotein (ox-LDL), as well as traditional risk factors, including age, sex, diabetes mellitus, hypercholesterolemia, high blood pressure, obesity, and smoking, were shown to have contributory effects on the development of atherosclerotic lesions. ${ }^{1,2}$ Under some pathological conditions, such as acute myocardial infarction (AMI) and coronary artery disease (CAD), increased levels of ox-LDL have been reported. Ox-LDL, which also regulates LOX-1 activity, shows pro-atherogenic effects through oxidized low density lipoprotein (lectin-like) receptor $1(O L R 1, L O X-1) .{ }^{3-6}$ The OLR 1 gene has been identified as a candidate gene which may be associated with AMI and CAD. ${ }^{3,4}$ OLR1 is induced by proatherogenic stimuli and by inflammatory cytokines, and it is upregulated in ischemia reperfusion injury in the rat. ${ }^{2,5,7}$

The OLR1 gene is mapped on 12p13.1-p12.3 constituting 6 exons and 5 introns. First 3 exons show functional consistency with different functional domains of protein (cytoplasmic, transmembrane and neck domain), and the other 3 exons encode the carbohydrate recognition domain and are similar to those in other C-type lectin genes. ${ }^{8}$ Seven polymorphisms have been identified on the OLR1 gene. Six of them (in intron 4, 5 and 3'UTR region) are in linkage disequilibrium (LD). ${ }^{9}$

Association studies have shown a role for the OLR1 gene variants in AMI susceptibility. In particular, 6 of the 7 singlenucleotide polymorphisms (SNPs) of the OLR1 gene located within intron 4 (IVS4-27G >C, IVS4-73C >T [rs3736234], IVS4-14A $>$ G [rs3736235]), intron 5 (IVS5-70A >G, IVS5-27G $>$ T) and 3'UTR (188C $>$ T) comprise a linkage disequilibrium block, which is strongly associated with the elevated risk of CAD. ${ }^{10,11}$

A new splicing isoform (lacking the exon 5) of the OLR1 gene with a new function is named LOXIN. ${ }^{9}$ In humans, the incidence of myocardial infarction was negatively associated with the LOXIN mRNA and protein expression levels. LOXIN lacks the ligand-binding site, but interacts with the full-length $O L R 1$ receptors by blocking their cellular expression, ox-LDL binding activity, and uptake. ${ }^{12}$ The expression of LOXIN mRNA is dramatically related to the OLR1 LD polymorphism. Macrophages of subjects with the "no risk" polymorphism have higher levels of mRNA as well as protein expression than macrophages of subjects carrying the risk haplotype. ${ }^{12}$ The OLR1 gene IVS4-14A>G (rs3736235) polymorphism influences the transcription of 2 isoforms OLR1/LOXIN, whose ratio could allow the identification of subjects who are at cardiovascular disease risk. Subjects carrying the mutant IVS4-14G allele express less LOXIN than those with the wild type IVS4-14A allele. ${ }^{12}$

The aim of the present work was to investigate the effects of the OLR1 IVS4-14A>G (rs3736235) and -73C>T (rs3736234) polymorphisms on lipid parameters in Turkish CAD patients and to show the linkage disequilibrium between these 2 polymorphisms.

\section{Material and methods}

\section{Patient selection and clinical investigation}

The study protocol was approved by both the Ethical Committee of the Faculty of Medicine and the Research Fund of Istanbul University, Turkey. All the procedures were in accordance with the Helsinki Declaration laid down in 1964 and its later amendments. All participants in study signed informed consent forms in accordance with ethics guidelines regarding the study. OLR1 IVS4$73 \mathrm{C}>\mathrm{T}$ and $-14 \mathrm{~A}>\mathrm{G}$ gene polymorphisms were studied in 97 patients with CAD (31 women, 66 men). The presence of CAD was documented by an angiography in patients with acute coronary syndrome. Angiographic inclusion criteria were: $\geq 50 \%$ stenosis of at least 1 major coronary vessel because of atherosclerosis, and a vascular event, defined as myocardial infarction, percutaneous transluminal coronary angioplasty or coronary artery by-pass grafting. ${ }^{13}$ Patients were included irrespective of concomitant risk factors for atherosclerosis such as smoking, arterial hypertension and diabetes mellitus.

To identify normal distribution of the OLR1 IVS4-73C >T and $-14 \mathrm{~A}>\mathrm{G}$ genotypes, we enrolled a control population of 78 healthy unrelated individuals ( 35 women, 43 men). This group primarily included the spouses of CAD patients and volunteers. A coronary angiography was not performed on these individuals, and therefore the presence of atherosclerotic coronary arteries could not be excluded. However, none of these individuals had any history of vascular event. Before the subjects were admitted into the study, their medical history was taken with special emphasis on coronary risk factors, including smoking, family history of CAD, hypertension, diabetes mellitus, and hyperlipidemia. The study was approved by the Ethics Committee of the Faculty of Medicine, Istanbul University, and written informed consent was obtained from each participant.

\section{Genotyping}

Genomic DNA was extracted from human leukocyte nuclei isolated from whole blood by standard methods. ${ }^{14}$ IVS4-73C $>\mathrm{T}$ and -14A>G genotypes were performed by the method described by Trabetti et al. ${ }^{7}$

\section{Statistical analysis}

All statistical analyses were performed by SPSS for Windows v. 20.0 (SPSS Inc., Chicago, USA). To evaluate the difference in the occurrence of the OLR1 IVS4-73C $>\mathrm{T}$ and $-14 \mathrm{~A}>\mathrm{G}$ genotypes in the study groups, the $\chi^{2}$ test was used. Differences in the distributions of genotypes according to clinical phenotypes (presence or absence of left ventricular hypertrophy - LVH) were assessed by using the $\chi^{2}$ test in $2 \times 2$ tables. In order to determine the relative 
risks, odds ratios (ORs) and 95\% confidence intervals (CIs) were used. Lipid and the other parametric analyses were compared by the Student's t and ANOVA tests. The linkage between the $-73 \mathrm{C}>\mathrm{T}$ and $-14 \mathrm{~A}>\mathrm{G}$ polymorphisms was assessed by using $D^{\prime}$ and $r^{2}$ values obtained through the Haploview Program (Broad Institute, Cambridge, USA) and p-values of $<0.05$ were considered as statistically significant.

\section{Results}

\section{Patient characteristics}

Demographic, biochemical and clinical data is summarized in Table 1. There were significant differences in the frequencies of the total cholesterol (TC) levels $(p=0.023)$ and smoking ( $\mathrm{p}=0.001$ ) between patients with CAD and the control subjects. However, no significant differences were detected in systolic and diastolic blood pressures, sex, BMI, concentrations of serum TG, LDL-cholesterol, HDL-cholesterol, and very low-density lipoprotein (VLDL) cholesterol between patients with CAD and the control subjects ( $\mathrm{p}>0.05)$.

Table 1. Characteristics of the study population

\begin{tabular}{|c|c|c|}
\hline Baseline characteristics & Control $(n=78)$ & $\operatorname{CAD}(n=97)$ \\
\hline Age [years] $(X \pm S D)$ & $58.05 \pm 10.43$ & $59.93 \pm 9.70$ \\
\hline Sex (women/men) (n) & $35 / 43$ & $31 / 66$ \\
\hline $\mathrm{BMI}\left[\mathrm{kg} / \mathrm{m}^{2}\right](\mathrm{X} \pm \mathrm{SD})$ & $25.19 \pm 3.63$ & $26.08 \pm 3.10$ \\
\hline $\mathrm{SBP}[\mathrm{mm} \mathrm{Hg}](\mathrm{X} \pm \mathrm{SD})$ & $121.53 \pm 13.46$ & $123.56 \pm 27.02$ \\
\hline $\mathrm{DBP}[\mathrm{mm} \mathrm{Hg}](X \pm S D)$ & $73.14 \pm 8.97$ & $77.02 \pm 16.62$ \\
\hline $\mathrm{TC}[\mathrm{mmol} / \mathrm{L}](X \pm \mathrm{SD})$ & $4.87 \pm 1.37$ & $5.40 \pm 1.36^{*}$ \\
\hline $\mathrm{TG}[\mathrm{mmol} / \mathrm{L}](\mathrm{X} \pm \mathrm{SD})$ & $1.56 \pm 0.71$ & $1.64 \pm 0.98$ \\
\hline HDL-cholesterol [mmol/L] $(X \pm S D)$ & $1.01 \pm 0.35$ & $0.98 \pm 0.19$ \\
\hline LDL-cholesterol [mmol/L] $(\mathrm{X} \pm \mathrm{SD})$ & $3.19 \pm 1.24$ & $3.41 \pm 1.15$ \\
\hline VLDL-cholesterol [mmol/L] $(\mathrm{X} \pm \mathrm{SD})$ & $0.73 \pm 0.40$ & $0.74 \pm 0.54$ \\
\hline Smoking (\%) & 46.3 & $69.1+$ \\
\hline Type 2 DM (\%) & - & 24.2 \\
\hline Hypertension (\%) & - & 38.2 \\
\hline LVH & - & 25.6 \\
\hline
\end{tabular}

The results are shown as $X$ (mean) \pm SD (standard deviation). CAD - patients with coronary artery disease; BMI - body mass index; SBP - systolic blood pressure; DBP - diastolic blood pressure; TC - total cholesterol; TG - triglyceride; HDL - high-density lipoprotein;

LDL - low-density lipoprotein; VLDL - very low-density lipoprotein; $\mathrm{LVH}$ - left ventricular hypertrophy; $\mathrm{n}$ - number of individuals; ${ }^{*} \mathrm{p}=0.023$; $+p=0.001$.

\section{Distributions of the OLR1 IVS4 -14A>G and IVS4 -73C>T genotypes}

The distributions of genotypes and alleles of OLR1 IVS4$73 \mathrm{C}>\mathrm{T}$ and $-14 \mathrm{~A}>\mathrm{G}$ are shown in Table 2 . No significant deviation from Hardy-Weinberg equilibrium (HWE) was observed for OLR1 IVS4 polymorphisms in the study
Table 2. The distributions of OLR1 IVS4-73C >T and IVS4-14A>G genotypes and alleles in the study groups

\begin{tabular}{|l|c|c|c|}
\hline \multicolumn{2}{|c|}{$\begin{array}{c}\text { Distributions of } \\
\text { studied OLR1 SNPs }\end{array}$} & Control group & CAD group \\
\hline IVS4-73C>T & CC & $4(5.1)$ & $n=91$ \\
\hline $\begin{array}{l}\text { Genotypes } \\
\text { n(\%) }\end{array}$ & TT & $25(32.1)$ & $8(8.8)$ \\
\hline Callele n(\%) & CT & $49(62.8)$ & $28(30.8)$ \\
\hline Tallele n(\%) & & $57(36.53)$ & $55(60.4)$ \\
\hline IVS4-14A>G & $99(63.46)$ & $71(39.01)$ \\
\hline \multirow{2}{*}{ Genotypes } & GG & $n=76$ & $111(60.98)$ \\
\hline (\%) & AG & $26(34.2)$ & $n=97$ \\
\hline A allele n(\%) & & $11(14.5)$ & $15(15.5)$ \\
\hline G allele n(\%) & & $91(59.86)$ & $60(61.9)$ \\
\hline
\end{tabular}

$\mathrm{X}^{2}$ test was used to compare genotypes in the study group. For determining allele frequencies gene count method was used.

$C A D$ - patients with coronary artery disease; $n$ - number of individuals.

groups $(\mathrm{p}>0.05)$. In addition, statistical analysis revealed no significant difference in the genotype and allele frequencies of OLR1 IVS4 in the study groups ( $\mathrm{p}>0.05)$.

\section{Haplotype analysis}

IVS4-14G allele carriers in the control group also carried IVS4-73T allele $(\mathrm{p}=0.008)$. Moreover, it was determined that most patients with IVS4-14 G allele carry IVS4-73T allele ( $\mathrm{p}<0.001)$ (Table 3). Therefore, we assessed haplotype analysis and found an observed LD with $\mathrm{D}^{\prime}=0.741$ between IVS4-14A $>\mathrm{G}$ and $-73 \mathrm{C}>\mathrm{T}$ polymorphisms $(\mathrm{p}>0.05)$ (Fig. 1). On the other hand, haplotype frequencies of IVS4$14 \mathrm{~A}>\mathrm{G}$ and IVS4-73C $>\mathrm{T}$ were estimated, and the

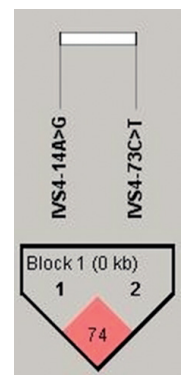

Fig. 1. The linkage disequilibrium (LD) analysis of IVS4-14A $>$ G and IVS4-73C >T

LD plot was generated by HaploView software v. 4.2. The pairwise LD value $\left(D^{1}=0-100\right)$ is given in the colored pink square with " 74 ", which indicates $D^{1}=0.74$ A value of $100\left(D^{1}=1\right)$ represents maximum possible linkage disequilibrium.

Table 3. Interactions between OLR1 IVS4-14A $>$ G and IVS4-73C >T variants

\begin{tabular}{|l|c|c|c|c|}
\multirow{2}{*}{ OLR1 IVS4-14AG } & \multicolumn{2}{|c|}{ Control group } & \multicolumn{2}{c}{ CAD group } \\
\cline { 2 - 5 } & \multicolumn{2}{|c|}{ OLR1 IVS4-73CT } & \multicolumn{2}{c|}{ OLR1 IVS4-73CT } \\
\cline { 2 - 5 } & CC & CT+TT & CC & CT+TT \\
\hline AA & $4(18.2 \%)$ & $18(81.8 \%)$ & $7(33.3 \%)$ & $14(66.7 \%)$ \\
AG+GG & - & $47(100 \%)$ & $1(5.5 \%)$ & $66(98.5 \%)$ \\
\hline p-value & \multicolumn{2}{|c|}{$p=0.008^{*}$} & \multicolumn{2}{|c|}{$p<0.001^{*}$} \\
\hline
\end{tabular}

$X^{2}$ test was used to compare genotypes in the study group. For determining allele frequencies gene count method was used. ${ }^{*} p<0.05$ indicates statistical significance (Fisher's exact test). 
Table 4. Haplotype associations of OLR1 IVS4-14A>G and -73C>T polymorphisms

\begin{tabular}{|l|c|c|c|c|}
\multirow{2}{*}{ Haplotype association } & \multicolumn{3}{|c|}{ Frequencies } & \multicolumn{2}{c|}{$X^{2}$} \\
\cline { 2 - 5 } & overall & patients & controls & 0.795 \\
\hline GT & 0.399 & 0.422 & 0.369 & 0.3726 \\
AC & 0.338 & 0.339 & 0.335 & 0.001 \\
\hline AT & 0.221 & 0.193 & 0.258 & 1.524 \\
GC & 0.043 & 0.046 & 0.038 & 0.217 \\
\hline
\end{tabular}

To evaluate the combined effect of $O L R 1$ IVS4-14A>G and $-73 C>$ T polymorphisms on CAD, the haplotype frequencies for significant loci and the standardized disequilibrium coefficient ( $D^{\prime}$ ) for pairwise linkage disequilibrium (LD) were calculated using $r^{2}$ and LOD values (LOD is the log of the likelihood odds ratio, $r^{2}$ is the correlation coefficient between the 2 loci). The $1^{\text {st }}$ allele indicates OLR1 IVS4-14A>G; the $2^{\text {nd }}$ allele indicates OLR1 IVS4-73C>T polymorphism.

$D^{\prime}=0.741 ; r^{2}=0.274 ; L O D=9.04 ; L D=74$.

following 4 haplotypes with frequency were observed: G-T (39.9\%); A-C (33.8\%); A-T (22.1\%); G-C (4.3\%) (p > 0.05) (Table 4).

\section{Association of the OLR1 IVS4-14A>G and IVS4-73C>T SNPs with lipid and metabolic parameters}

Patients with IVS4-14 G allele (AG+GG genotypes) have significantly higher LDL-cholesterol levels $(p=0.027)$ (Fig. 2) and higher TC, as close to statistical significance ( $p=0.063$ ) (Fig. 3) than patients with IVS4-14AA genotypes (Table 5). Also, we found that the controls carrying
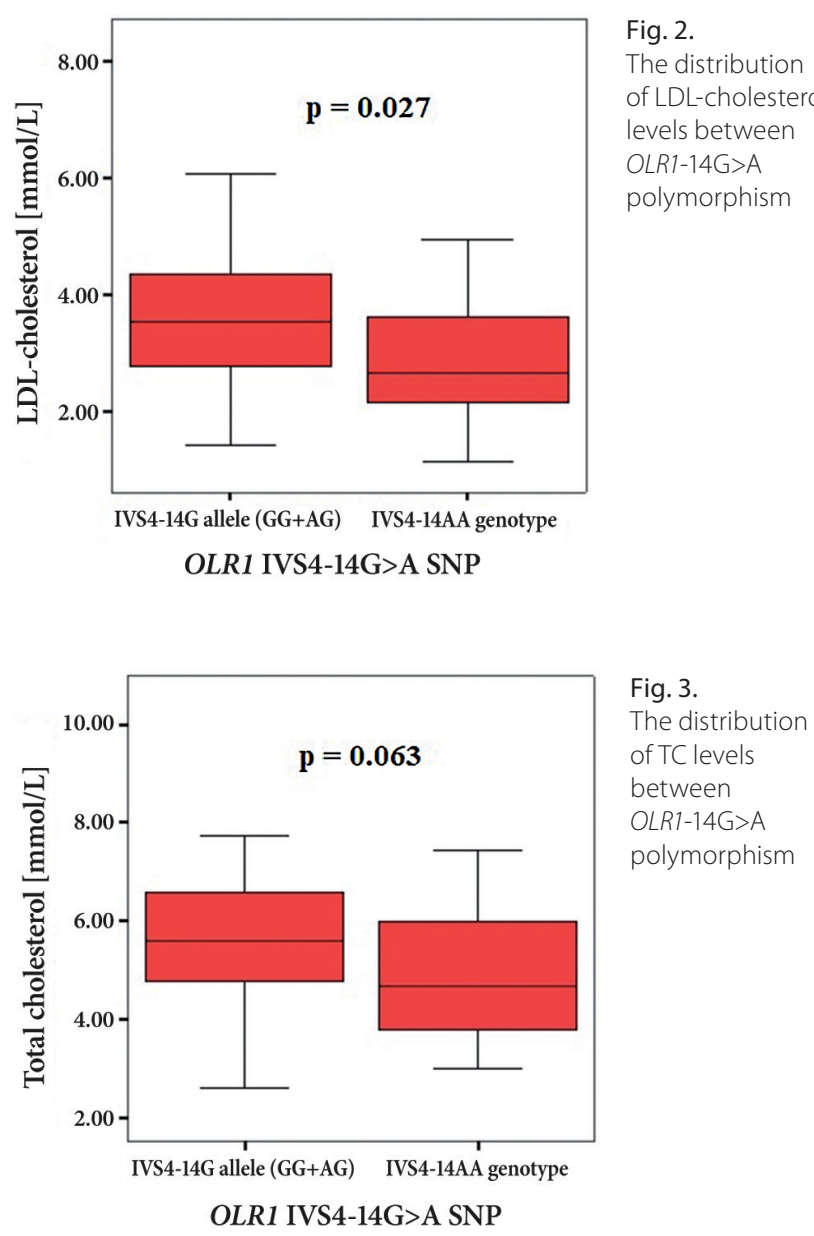

The distribution of LDL-cholesterol levels between OLRT-14G>A polymorphism the $-14 \mathrm{G}$ allele were prone to high levels of LDL-cholesterol $(12.5 \%)$ and TC (10.08\%) without any statistical significance (Table 5).

As shown in Table 5, in patients with IVS4-73 T allele $(\mathrm{CT}+\mathrm{TT})$, the BMI values increased compared to those with IVS4-73 CC genotype ( $\mathrm{p}=0.046)$, while they decreased in the controls with $\mathrm{T}$ allele compared to those with CC genotype $(\mathrm{p}=0.024)$. When we analyzed the effects of IVS4 -73 variant on the serum lipid profile, it was observed that the HDL-cholesterol levels were statistically lower in the control subjects with IVS4-73 T allele than in those with IVS4-73 CC genotype ( $\mathrm{p}=0.002)$ (Table 5). Also, SBP levels were statistically higher in the IVS4-73C allele carriers $(\mathrm{CT}+\mathrm{CC})$ than in the IVS4-73TT genotype carriers (C allele: 127.17 \pm 30.09 vs TT genotype: $115.83 \pm 19.76$; $\mathrm{p}=0.045$ ) in the group of patients (Table 5).

\section{Discussion}

Genetic risk factors are considered to be responsible for about half of CAD events. In recent years, several functional SNPs of the OLR1 gene have been associated with CAD in humans. One of these functional SNPs is the IVS4-14A>G. ${ }^{15}$ IVS4-14A allele encodes a truncated OLR1 splice isoform, LOXIN, which lacks a part of the extracellular domain resulting in reduced binding capacity for ox-LDLs, and the cellular expression of the full-length $O L R 1$ receptors and their ox-LDL binding activity. ${ }^{15,16}$ LOXIN expression provides increased resistance to ox-LDL-induced macrophage apoptosis and atherogenesis in vitro. It was shown that IVS4-14A allele carriers are protected from cardiovascular disease, whereas homozygous IVS4-14G allele carriers are predisposed to cardiovascular disease in vivo. ${ }^{3,15}$ However, the effect of the OLR1 IVS4-14A>G SNP on lipoprotein metabolism has not yet been investigated.

Chen et al. reported that the intron $4 / \mathrm{G}$ allele frequencies of the OLR1 gene were higher in the white population than in the black population in Women's Ischemia Syndrome Evaluation (WISE) Study (49.2\% vs $18.8 \%$; $\mathrm{p}<0.001) .{ }^{10}$ In the WISE study, it was found an association between the common genetic 3 'UTR $188 \mathrm{C}>\mathrm{T}$ variation in the OLR1 
Table 5. The effects of OLR1 IVS4-73C>T and IVS4-14A>G genotypes and alleles on serum lipoprotein levels, BMI and blood pressure in patients group

\begin{tabular}{|c|c|c|c|c|c|c|c|c|}
\hline \multirow{2}{*}{ Groups } & \multicolumn{4}{|c|}{ OLR1 IVS4-14A>G genotypes } & \multicolumn{4}{|c|}{ OLR1 IVS4-73C>T genotypes } \\
\hline & AA & $\mathrm{AG}+\mathrm{GG}$ & GG & $\mathrm{AG}+\mathrm{AA}$ & CC & $\mathrm{CT}+\mathrm{TT}$ & TT & $\mathrm{CT}+\mathrm{CC}$ \\
\hline \multicolumn{9}{|c|}{ Control } \\
\hline $\mathrm{TC}[\mathrm{mmol} / \mathrm{L}]$ & $4.66 \pm 1.10$ & $5.23 \pm 1.35$ & $5.31 \pm 1.15$ & $4.99 \pm 1.33$ & $5.02 \pm 0.91$ & $4.90 \pm 1.40$ & $4.88 \pm 1.29$ & $4.92 \pm 1.43$ \\
\hline $\mathrm{TG}[\mathrm{mmol} / \mathrm{L}]$ & $1.70 \pm 1.29$ & $1.79 \pm 0.75$ & $1.77 \pm 0.90$ & $1.77 \pm 0.99$ & $2.41 \pm 0.97$ & $1.69 \pm 0.94$ & $1.90 \pm 0.87$ & $1.66 \pm 0.99$ \\
\hline $\mathrm{HDL}-\mathrm{C}[\mathrm{mmol} / \mathrm{L}]$ & $0.97 \pm 0.27$ & $0.98 \pm 0.37$ & $1.05 \pm 0.52$ & $0.96 \pm 0.30$ & $1.02 \pm 0.35$ & $0.89 \pm 0.08 \S$ & $1.06 \pm 0.45$ & $0.97 \pm 0.36$ \\
\hline LDL-C [mmol/L] & $3.03 \pm 0.97$ & $3.41 \pm 1.38$ & $3.35 \pm 0.81$ & $3.27 \pm 1.34$ & $3.22 \pm 0.72$ & $3.23 \pm 1.28$ & $3.03 \pm 1.11$ & $3.33 \pm 1.31$ \\
\hline VLDL-C [mmol/L] & $0.77 \pm 0.33$ & $0.80 \pm 0.60$ & $0.81 \pm 0,41$ & $0.78 \pm 0.47$ & $0.80 \pm 0.46$ & $0.74 \pm 0.43$ & $0.76 \pm 0.40$ & $077 \pm 0.45$ \\
\hline BMI [kg/m²] & $25.46 \pm 3.44$ & $24.93 \pm 3.21$ & $23.53 \pm 3.06$ & $25.40 \pm 3.25$ & $29.26 \pm 3.92$ & $25.03 \pm 3.55 a$ & $25.51 \pm 4.82$ & $25.17 \pm 3.14$ \\
\hline $\mathrm{SBP}[\mathrm{mm} \mathrm{Hg}]$ & $122.72 \pm 16.08$ & $120.42 \pm 7.43$ & $119.09 \pm 7.00$ & $121.55 \pm 11.48$ & $117.50 \pm 5.00$ & $120.97 \pm 11.58$ & $121.19 \pm 16.27$ & $120.60 \pm 8.67$ \\
\hline $\mathrm{DBP}[\mathrm{mm} \mathrm{Hg}]$ & $70.0 \pm 9.25$ & $73.51 \pm 7.21$ & $70.98 \pm 9.44$ & $72.67 \pm 7.99$ & $67.50 \pm 5.00$ & $73.58 \pm 8.60$ & $75.71 \pm 14.54$ & $72.20 \pm 6.79$ \\
\hline \multicolumn{9}{|c|}{ Patients } \\
\hline $\mathrm{TC}[\mathrm{mmol} / \mathrm{L}]$ & $4.96 \pm 1.32$ & $5.58 \pm 1.35^{*}$ & $5.67 \pm 151$ & $5.39 \pm 1.34$ & $5.03 \pm 1.41$ & $5.42 \pm 1.37$ & $5.27 \pm 1.55$ & $5.43 \pm 1.31$ \\
\hline $\mathrm{TG}[\mathrm{mmol} / \mathrm{L}]$ & $1.46 \pm 0.73$ & $1.76 \pm 1.15$ & $1.81 \pm 0.85$ & $1.67 \pm 1.11$ & $1.45 \pm 0.77$ & $1.71 \pm 1.12$ & $1.65 \pm 0.83$ & $1.71 \pm 1.19$ \\
\hline $\mathrm{HDL}-\mathrm{C}[\mathrm{mmol} / \mathrm{L}]$ & $1.05 \pm 0.31$ & $1.09 \pm 0.30$ & $0.94 \pm 0.21$ & $1.02 \pm 0.31$ & $1.00 \pm 0.45$ & $1.10 \pm 0.29$ & $1.01 \pm 0.32$ & $0.98 \pm 0.28$ \\
\hline LDL-C [mmol/L] & $2.94 \pm 1.04$ & $3.58 \pm 1.15 t$ & $3.57 \pm 1.32$ & $3.40 \pm 1.12$ & $2.78 \pm 1.06$ & $3.45 \pm 1.16$ & $3.38 \pm 1.20$ & $3.39 \pm 1.17$ \\
\hline VLDL-C [mmol/L] & $0.66 \pm 0.31$ & $0.78 \pm 0.30$ & $0.83 \pm 0.42$ & $0.74 \pm 058$ & $0.64 \pm 0.30$ & $0.77 \pm 0.58$ & $0.74 \pm 0.41$ & $0.78 \pm 0.42$ \\
\hline BMI $\left[\mathrm{kg} / \mathrm{m}^{2}\right]$ & $26.25 \pm 3.35$ & $26.10 \pm 3.07$ & $26.33 \pm 3.04$ & $26.09 \pm 3.16$ & $24.50 \pm 1.76$ & $26.41 \pm 3.20 ¥$ & $26.38 \pm 3.12$ & $26.22 \pm 3.19$ \\
\hline $\mathrm{SBP}[\mathrm{mm} \mathrm{Hg}]$ & $120.0 \pm 19.76$ & $124.13 \pm 29.11$ & $122.0 \pm 25.69$ & $123.36 \pm 27.54$ & $124.37 \pm 19.89$ & $123.97 \pm 28.75$ & $115.83 \pm 19.76$ & $127.17 \pm 30.09 \psi$ \\
\hline $\mathrm{DBP}[\mathrm{mm} \mathrm{Hg}]$ & $75.45 \pm 11.00$ & $76.95 \pm 18.15$ & $74.33 \pm 18.98$ & $77.04 \pm 16.27$ & $78.12 \pm 14.12$ & $77.37 \pm 17.57$ & $72.71 \pm 15.25$ & $79.27 \pm 17.69$ \\
\hline
\end{tabular}

The results are shown as mean \pm standard deviation. TC - total cholesterol; TG - triglyceride; HDL-C - high-density lipoprotein cholesterol; LDL-C - lowdensity lipoprotein cholesterol; VLDL-C - very low-density lipoprotein cholesterol; BMI - body mass index; SBP - systolic blood pressure; DBP - diastolic blood pressure. Statistical analyses were performed by using the Student's t-test. ${ }^{*} p=0.063 ; \uparrow p=0.027 ; \S p=0.002 ; a p=0.024 ; ¥ p=0.046 ; \psi p=0.045$.

gene and stenosis severity of CAD. They also suggested that the IVS4 $-14 \mathrm{~A}>\mathrm{G}$, the intron $5 \mathrm{~T}>\mathrm{G}$ and the 3'UTR $188 \mathrm{C}>\mathrm{T}$ polymorphisms of the OLR 1 gene were in significant linkage disequilibrium, and therefore exhibited similar genotype/allele frequencies. They asserted that all 3 polymorphisms could be considered a single marker for discussion purpose. They also found no significant association between OLR1 polymorphisms (in the intron $4 \mathrm{G}>\mathrm{A}$ the intron $5 \mathrm{~T}>\mathrm{G}$, and the 3'UTR $\mathrm{T}>\mathrm{C}$ ) and plasma lipid levels (TC, LDL-cholesterol, HDL-cholesterol, and TG). ${ }^{10}$

Trabetti et al. found a similar distribution frequency of the IVS4-73TT homozygous allele among AMI and nonAMI cases. ${ }^{7}$ They observed the association between the IVS4-73C $>\mathrm{T}$ and CAD, as close to statistical significance $(\mathrm{p}=0.065)$. Mango et al. examined 7 OLR1 polymorphisms (K167N, 3'UTR 188C >T, IVS4+27G>C, IVS4-73C>T, IVS4-14A $>$ G, IVS5-70A $>$ G, IVS5-27G $>$ T) and found that 6 of them (except K167N) comprised a linkage disequilibrium block behaving as a single SNP.11

In the present study, no significant associations were observed between OLR1 IVS4-73C $>\mathrm{T}$ and $-14 \mathrm{~A}>\mathrm{G}$ genotypes and alleles and the risk of CAD ( $p>0.05)$. In general, serum lipid pattern was shown to indicate a predisposition to hyperlipidemic profile, as an independent CAD risk factor. In patients with CAD, IVS4-14G allele was associated with moderately higher cholesterol levels (in excess of 12\%) in its carriers than in the IVS4-14AA genotype carriers $(\mathrm{p}=0.063)$. When we investigated the effects of the IVS4$73 \mathrm{C}>\mathrm{T}$ SNP on serum lipid levels and other characteristics in the controls, we observed that the HDL-cholesterol levels and BMI were lower in the IVS4 -73 T allele (CT+TT genotype) carriers than in non-carriers (CC genotype) $(\mathrm{p}=0.002$ and $\mathrm{p}=0.024$, respectively). In healthy controls with IVS4-73CC genotype, BMI was higher than in controls with TT and CT genotypes ( $\mathrm{p}>0.05)$. In contrast to detrimental effects of IVS4-73 T allele on lipids, it was related to a favorable effect on BMI. Although the distribution of OLR1 IVS4-14A $>$ G and IVS4-73C $>$ T SNPs was similar in patient and control groups, it was observed that the 2 IVS4 polymorphisms of the $O L R 1$ gene were in a very high linkage disequilibrium ( $\left.D^{\prime}=0.74 ; r^{2}=0.274\right)$. This finding indicates that both of the IVS4 SNPs of the OLR1 gene can be inherited together. Furthermore, the OLR1 IVS4-14A>G SNP has an unfavorable lipid profile (high total and LDL-cholesterol levels), though it is not associated with the risk of CAD.

Several studies reported that the OLR1 3'UTR 188C $>$ T and IVS4-73C $>$ T SNPs were in a linkage disequilibrium block. ${ }^{10,11}$ In our previous study, 3'UTR 188TT genotype was associated with increased SBP levels in patients with CAD. ${ }^{1}$ Moreover, we found that the SBP levels were statistically higher in the normal IVS4-73C allele carriers $(\mathrm{CT}+\mathrm{CC})$ than in the rare homozygote IVS4-73TT genotype carriers $(115.83 \pm 19.76$ vs $127.17 \pm 30.09 ; \mathrm{p}=0.045)$ 
in the group of patients. When we analyzed these SNPs $(-73 \mathrm{C}>\mathrm{T}$ and 3'UTR $188 \mathrm{C}>\mathrm{T})$, our findings showed that most of the IVS4-73C allele carriers also have OLR1 3'UTR $188 \mathrm{~T}$ allele $(89.5 \%)$. This finding suggests the possibility of an interaction between these 2 SNPs $(-73 \mathrm{C}>\mathrm{T}$ and 3'UTR $188 \mathrm{C}>\mathrm{T}$ ) and hypertension in the presence of CAD. Although the definite mechanism requires further research, we think that the intron 4 variations of the $O L R 1$ gene may result in an increased risk of CAD by increasing the SBP levels.

As a conclusion, our study is the first one to investigate the IVS4-14A $>\mathrm{G}$ and $-73 \mathrm{C}>\mathrm{T}$ variants of the $O L R 1$ gene in the Turkish population. It was shown that the IVS4-14A $>$ G and -73C $>$ T SNPs of the OLR1 gene comprise a linkage disequilibrium block. Our results are in agreement with the hypothesis that the intron 4 SNPs of the OLR1 gene are inherited together. The $-14 \mathrm{~A}>\mathrm{G}$ SNP was associated with increased levels of TC and LDLcholesterol in the patient group, while normal homozygote $-73 C$ genotype was associated with increased levels of HDL-cholesterol in the control subjects. The present findings suggest that the OLR1 gene IVS4 gene variants might play a role in hypercholesterolemia as an independent CAD risk factor in the Turkish population.

\section{References}

1. Kurnaz $O$, Akadam-Teker AB, Yilmaz-Aydoğan $H$, Tekeli A, Isbir T. The LOX-1 3'UTR188CT polymorphism and coronary artery disease in Turkish patients. Mol Biol Rep. 2012;39(4):4351-4358.

2. Mango R, Predazzi IM, Romeo F, Novelli G. LOX-1/LOXIN: The yin/ yang of atheroscleorosis. Cardiovasc Drugs Ther. 2011;25:489-494.

3. Vecchione L, Gargiu E, Borgiani P, et al. Genotyping OLR1 gene: A genomic biomarker for cardiovascular diseases. Recent Pat Cardiovasc Drug Discov. 2007;2(2):147-151.
4. Freeman MW. Scavenger receptors in atherosclerosis. Curr Opin Hematol. 1997;4:41-47.

5. Ishigaki T, Ohki I, Utsunomiya-Tate N, Tate SI. Chimeric structural stabilities in the coiled-coil structure of the NECK domain in human lectin-like oxidized low-density lipoprotein receptor 1 (LOX-1). J Biochem. 2007;141(6):855-866.

6. Steinbrecher UP. Receptors for oxidized low density lipoprotein. Biochim Biophys Acta. 1999;1436:279-298.

7. Trabetti E, Biscuola M, Cavallari U, et al. On the association of the oxidised LDL receptor 1 (OLR1) gene in patients with acute myocardial infarction or coronary artery disease. Eur JHum Genet. 2006;14:127-130.

8. Mehta JL, Chen J, Hermonat PL, Romeo F, Novelli G. Lectin-like oxidized low-density lipoprotein receptor-1(LOX-1): A critical player in the development of atherosclerosis and related disorders. Cardiovasc Res. 2006;69:36-45.

9. Mango R, Biocca S, Del Vecchio F, et al. In vivo and in vitro studies supports that a new splicing isoform of OLR1 gene is protective against acute myocardial infarction. Circ Res. 2005;97:152-158.

10. Chen $Q$, Reis SE, Kammerer C, et al. Genetic variation in lectin-like oxidized low-density lipoprotein receptor 1(LOX1) gene and the risk of coronary artery disease. Circulation. 2003;107:3146-3151.

11. Mango R, Clementi F, Borgiani $P$, et al. Association of single nucleotide polymorphisms in the oxidised LDL receptor 1 (OLR1) gene in patients with acute myocardial infarction. J Med Genet. 2003;40:933-936.

12. Gambino R, Bo S, Musso G, Pagano G, Cassader M. Loxin polymorphism is associated with increased resistin levels and with oxidative status. Clin Biochem. 2011;44:1015-1017.

13. Sahn DJ, De Maria A, Kisslo J, Weyman A. Recommendations regarding quantitation in M-mode echocardiography: Result of a survey of echocardiographic measurements. Circulation. 1978;58:1072-1083.

14. Miller SA, Dykes DD, Poleskey HS. A simple salting out procedure for extracting DNA from human nucleated cells. Nucleic Acids Res. 1988;16:1215.

15. Musso G, Cassader M, Michieli FD, Saba F, Bo S, Gambino R. Effect of lectin-like oxidized LDL receptor-1 polymorphism on liver disease, glucose homeostasis, and postprandial lipoprotein metabolism in nonalcoholic steatohepatitis. Am J Clin Nutr. 2011;94:1033-1042.

16. Takanabe-Mori R, Ono K, Sowa N, et al. Lectin-like oxidized low-density lipoprotein receptor-1 is required for the adipose tissue expression of proinflammatory cytokines in high-fat diet-induced obese mice. Biochem Biophys Res Commun. 2010;398:576-80. 